\title{
Crystal structure of nitrogen regulatory protein IIANtr from Neisseria meningitidis
}

\author{
Jingshan Ren ${ }^{2}$, Sarah Sainsbury ${ }^{1}$, Nick S Berrow ${ }^{1}$, David Alderton ${ }^{1}$, \\ Joanne E Nettleship ${ }^{1}$, David K Stammers ${ }^{1,2}$, Nigel J Saunders ${ }^{3}$ and \\ Raymond J Owens*1
}

\begin{abstract}
Address: 1The Oxford Protein Production Facility, Henry Wellcome Building for Genomic Medicine, University of Oxford, Roosevelt Drive, Oxford OX3 7BN, UK, 2Division of Structural Biology, Henry Wellcome Building for Genomic Medicine, University of Oxford, Roosevelt Drive, Oxford, OX3 7BN, UK and ${ }^{3}$ The Bacterial Pathogenesis and Functional Genomics Group, The Sir William Dunn School of Pathology, University of Oxford, South Parks Road, Oxford, OX1 3RE, UK

Email: Jingshan Ren - ren@strubi.ox.ac.uk; Sarah Sainsbury - sarah@strubi.ox.ac.uk; Nick S Berrow - nick@strubi.ox.ac.uk; David Alderton - alderton@strubi.ox.ac.uk; Joanne E Nettleship - joanne@strubi.ox.ac.uk; David K Stammers - daves@strubi.ox.ac.uk; Nigel J Saunders - nigel.saunders@path.ox.ac.uk; Raymond J Owens* - ray@strubi.ox.ac.uk

* Corresponding author
\end{abstract}

Published: 10 August 2005

BMC Structural Biology 2005, 5:13 doi:10.1 186/1472-6807-5-13
Received: 14 April 2005

Accepted: 10 August 2005

This article is available from: http://www.biomedcentral.com/1472-6807/5//3

(c) 2005 Ren et al; licensee BioMed Central Ltd.

This is an Open Access article distributed under the terms of the Creative Commons Attribution License (http://creativecommons.org/licenses/by/2.0), which permits unrestricted use, distribution, and reproduction in any medium, provided the original work is properly cited.

\begin{abstract}
Background: The NMB0736 gene of Neisseria meningitidis serogroup B strain MC58 encodes the putative nitrogen regulatory protein, IIANtr (abbreviated to NM-IIANtr). The homologous protein present in Escherichia coli is implicated in the control of nitrogen assimilation. As part of a structural proteomics approach to the study of pathogenic Neisseria spp., we have selected this protein for structure determination by X-ray crystallography.
\end{abstract}

Results: The NM-IIANtr was over-expressed in E. coli and was shown to be partially monophosphorylated, as assessed by mass spectrometry of the purified protein.

Crystals of un-phosphorylated protein were obtained and diffraction data collected to $2.5 \AA$ resolution. The structure of NM-IIA ${ }^{\mathrm{Ntr}}$ was solved by molecular replacement using the coordinates of the $E$. coli nitrogen regulatory protein IIA ${ }^{\text {ntr }}[\mathrm{PDB}: \underline{\mid \mathrm{A} 6]}]$ as the starting model. The overall fold of the Neisseria enzyme shows a high degree of similarity to the IIANtr from E. coli, and the position of the phosphoryl acceptor histidine residue $(\mathrm{H} 67)$ is conserved. The orientation of an adjacent arginine residue (R69) suggests that it may also be involved in coordinating the phosphate group. Comparison of the structure with that of E. coli IIA ${ }^{\mathrm{mtl}}$ complexed with HPr [PDB: $\left.116 \mathrm{~T}\right]$ indicates that NM-IIANtr binds in a similar way to the HPr-like enzyme in Neisseria.

Conclusion: The structure of NM-IIANtr confirms its assignment as a homologue of the IIANtr proteins found in a range of other Gram-negative bacteria. We conclude that the NM- IIANtr protein functions as part of a phosphorylation cascade which, in contrast to $E$. coli, shares the upstream phosphotransfer protein with the sugar uptake phosphoenolpyruvate:sugar phosphotransferase system (PTS), but in common with $E$. coli has a distinct downstream effector mechanism. 


\section{Background}

Neisseria spp. are Gram-negative Beta-Protobacteria which include many species found only in humans. Two Neisseria spp. are pathogenic to human: $N$. meningitidis and $N$. gonorrhoeae, responsible for bacterial meningitis and septicaemia, and gonorrhoea, respectively. In the last few years, the genomes of $N$. meningitidis serotypes A (strain Z2491) [1] and B (strain MC58) [2] and N. gonorrhoeae (strain FA1090) (currently unpublished) have been sequenced and annotated. As part of a structural proteomics approach to the study of pathogenic Neisseria, we have solved the structure of the putative nitrogen regulatory protein IIA ${ }^{\mathrm{Ntr}}$ of $N$. meningitidis (abbreviated to NM-IIA ${ }^{\mathrm{Ntr}}$ ) (Gene NMB0736), the sequence of which is highly conserved amongst the Neisseria spp.

In Escherichia coli, the IIA ${ }^{\mathrm{Ntr}}$ gene ( $\left.p t s N\right)$ is located within the sigma-54 factor coding operon, $r p o N$, with which it is co-transcribed [3]. Insertional mutagenesis of $p t s N$ has been shown to suppress the conditional lethality of temperature sensitive era (era ${ }^{\text {ts }}$ ) mutants [4]. The era gene of E. coli encodes a GTPase which appears to be essential for cell growth [5]. IIA ${ }^{\mathrm{Ntr}}$ is a member of the mannitol-fructose family of IIA protein/domains which forms part of the phosphoenolpyruvate: sugar phosphotransferase system (PTS) [4]. PTS controls sugar uptake by bacteria through a series of phosphoryl transfer reactions in which the sugar-specific IIA enzyme is phosphorylated on a highly conserved histidine residue by the histidine-containing phosphocarrier protein, HPr [6]. In E. coli, the $r p o N$ operon also includes a gene encoding a protein related to $\mathrm{HPr}$, designated NPr; both HPr and NPr have been shown to phosphorylate E. coli IIANtr [4]. The sequence similarity between HPr and the molybdenumiron protein of the nitrogenase complex of Rhizobium trifolii [6] and the frequent association of PTS proteins with rpoN have been taken to suggest that IIANtr may provide a regulatory link between carbon and nitrogen assimilation in bacteria [7].

The role of the NM-IIANtr in Neisseria has not been characterized, and the potential functions of these proteins in cellular behaviour are diverse [8]. The gene encoding this protein is not found in proximity to the equivalent of the E. coli rpoN gene (NMB0217, which may not be functional) nor is it close to the HPr-like protein (NMB2045). The structures of the E. coli IIANtr [9] and related IIAmannitol $\left(\right.$ IIA $^{\mathrm{mtl}}$ ) domain of PTS [10] have been solved by X-ray crystallography. More recently, a solution structure of a phosphoryl transfer complex between IIAmtl domain and HPr has been described [11]. In this report, we compare the structure of the neisserial IIANtr to the homologous $E$. coli enzymes and complex and discuss the functional implications of our findings.

\section{Results and discussion Expression and purification}

The NM-IIA ${ }^{\mathrm{Ntr}}$ was over-expressed in E. coli with an N-terminal His-tag which was removed prior to crystallization. Mass spectrometric analysis of the purified protein showed that it comprised a 60:40 mixture of mono-phosphorylated and un-phosphorylated protein. The conserved $\mathrm{H} 67$ in the protein was thus capable of phosphorylation by endogenous $\mathrm{HPr} / \mathrm{NPr}$ from the expression system. Analyses of re-dissolved crystals of the protein by mass spectrometry showed that only the unphosphorylated form of the protein was crystallized presumably due to labile nature of the phospho-histidine bond in the acidic crystallisation conditions, $0.1 \mathrm{M}$ sodium citrate, $\mathrm{pH} 4$ (data not shown).

\section{Overall structure}

The model of NM-IIA ${ }^{\mathrm{Ntr}}$ contains 146 (out of 149) protein residues and 72 water molecules. Residues 1 and 148-149 are not modelled in the structure due to lack of clearly defined electron density. The structure of NM-IIANtr consists of a 5 -stranded mixed $\beta$-sheet which is sandwiched by six $\alpha$-helices, two on one side and four on the other (Fig. 1a \&1b). The overall fold, as expected from the sequence homology, is similar to that of E. coli IIANtr (34 $\%$ sequence identity) and IIA ${ }^{\mathrm{mtl}}$ (23\% sequence identity). 122 Cos out of 150 of E. coli IIA ${ }^{\text {Ntr }}$ [PDB: 1 A6I] can be overlapped onto NM-IIA ${ }^{\mathrm{Ntr}}$ with a root mean square deviation (rmsd) of $0.78 \AA$. The major differences between the neisserial and $E$. coli structures appear at surface loops linking the secondary structure elements, for examples $\alpha 2-\alpha 3, \beta 3-\beta 4$ and $\beta 5-\alpha 4$ loops (residues $34-40,70-75$ and 107-112 respectively in NM-IIA ${ }^{\mathrm{Ntr}}$ ), and the termini (Fig. 1c). The $\alpha 1$ is shorter and there is a one residue insertion at the $\alpha 2-\alpha 3$ loop in NM-IIANtr. Whilst comparison of E. coli IIAmtl [PDB: 1A3A] with NM-IIANtr gave 120 equivalent $C \alpha$ s with an rmsd of $1.48 \AA$. E. coli IIA $^{\text {mtl }}$ does not have the short $\alpha$-helix at the $N$-terminus, but has a extra helix between $\beta 3$ and $\beta 4$. Residue insertions and deletions at $\alpha 2-\alpha 3, \beta 3-\beta 4$ and $\beta 5-\alpha 4$ loops have resulted in large structural differences at these places between the two proteins (Fig. 1d). Similar differences between E. coli IIA $^{\mathrm{Nt}}$ and IIA ${ }^{\mathrm{mtl}}$ have been noted [12].

\section{Active site and interface with $\mathbf{H}-\mathbf{P r}$}

The active site of NM-IIANtr is located in a concave area of protein surface consisting of $\alpha 3-\alpha 4$ and $\beta 2-\beta 3$. The active site residue, $\mathrm{H} 67$, the equivalent of $\mathrm{H} 73$ in $E$. coli IIA $^{\mathrm{Ntr}}$ or H65 in E. coli IIA $^{\mathrm{mtl}}$, is the fifth residue of $\beta 3$ and is surrounded by hydrophobic residues L69, I65, L114, L117 and A121 on one side, and by hydrophilic residues R51 and R69 on the other side (Fig. 2a). H67 and R51 are conserved amongst all IIANtr and IIAmtl proteins. H67 is stabilized by a hydrogen bond to the carbonyl oxygen of L65 from its ND1 atom, while the NH1 atom of the R51 side- 
a

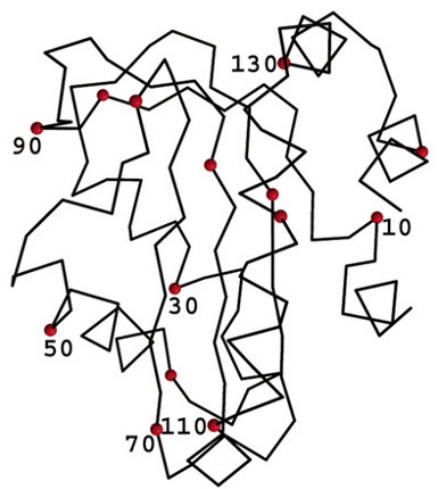

b

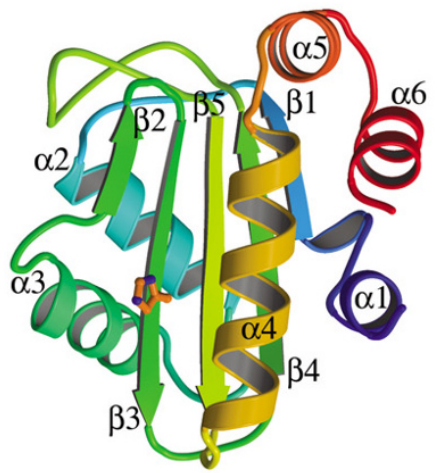

C

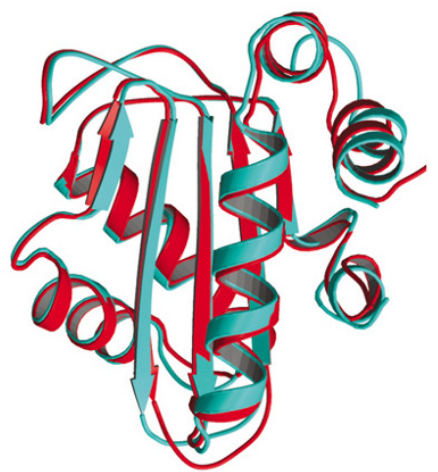

d

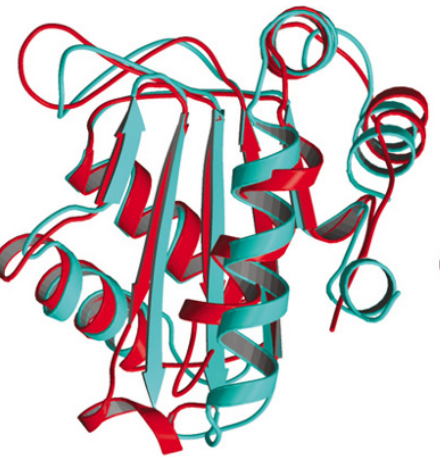

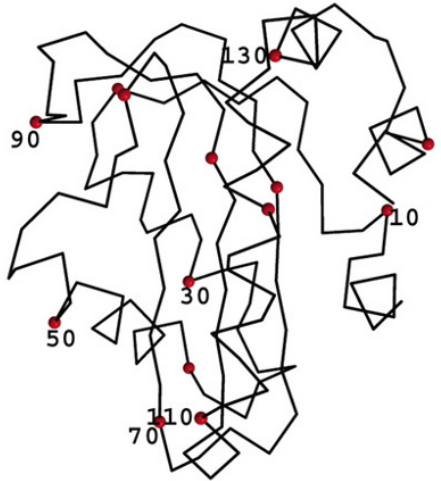
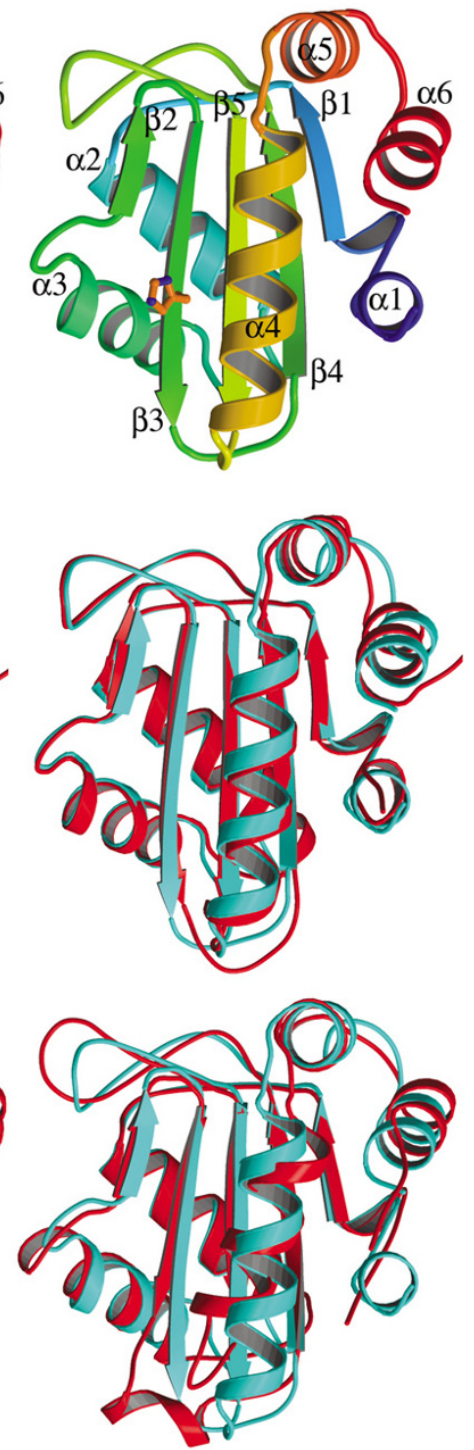

Figure I

Structure of NM-IIAntr. (a) Stereo figure of a $C_{\alpha}$-trace of NM-IIANtr with every twentieth residue numbered (b) Stereo figure of a ribbon diagram of NM-IIA Ntr with secondary structure elements labelled ( $\alpha$-helices I-4; $\beta$-strands I-5). The active site residue $\mathrm{H} 67$ is displayed as ball-and-stick. (c) Stereo figure of an overlay of NM-IIANtr (green) and E. colillANtr (red) (d) Stereo figure of an overlay of NM-IIA Ntr(green) and E. coli IIA mtl(red). 
a
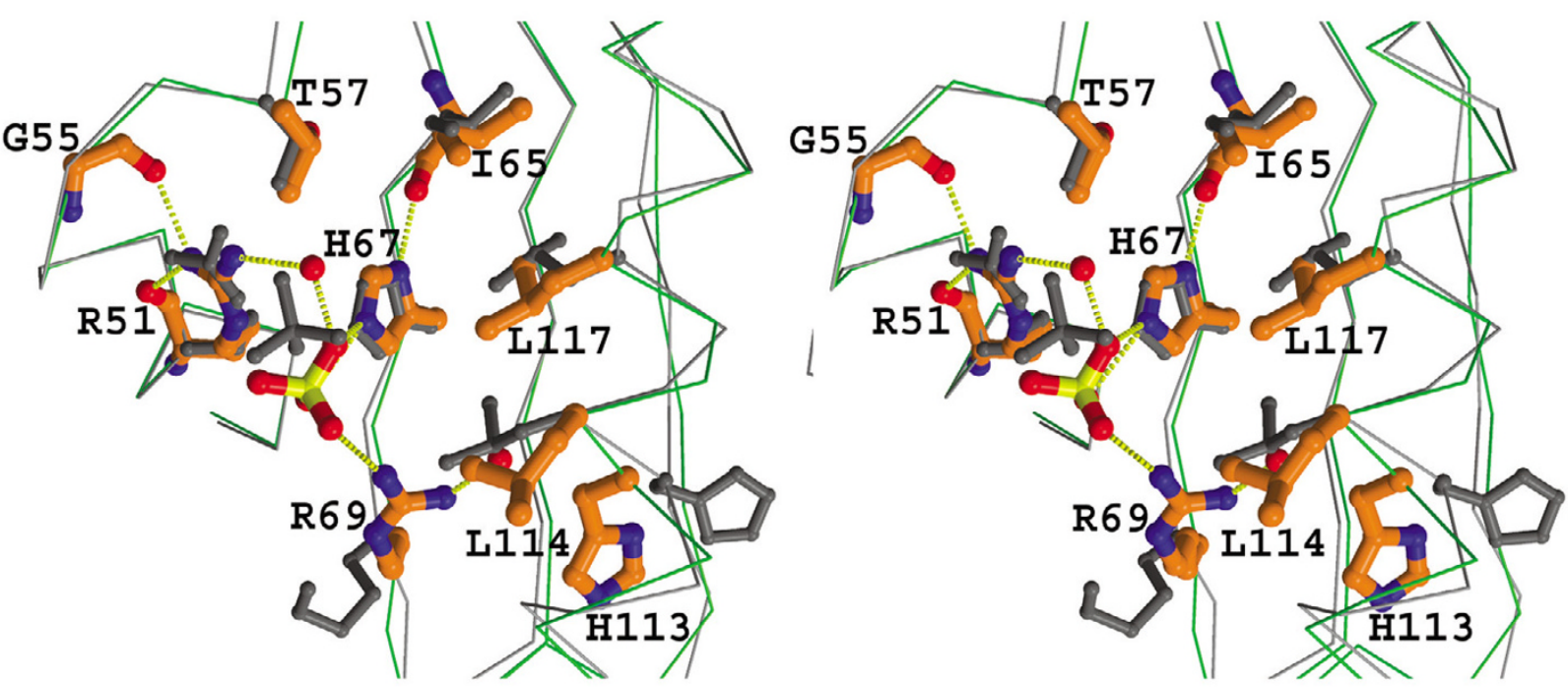

b
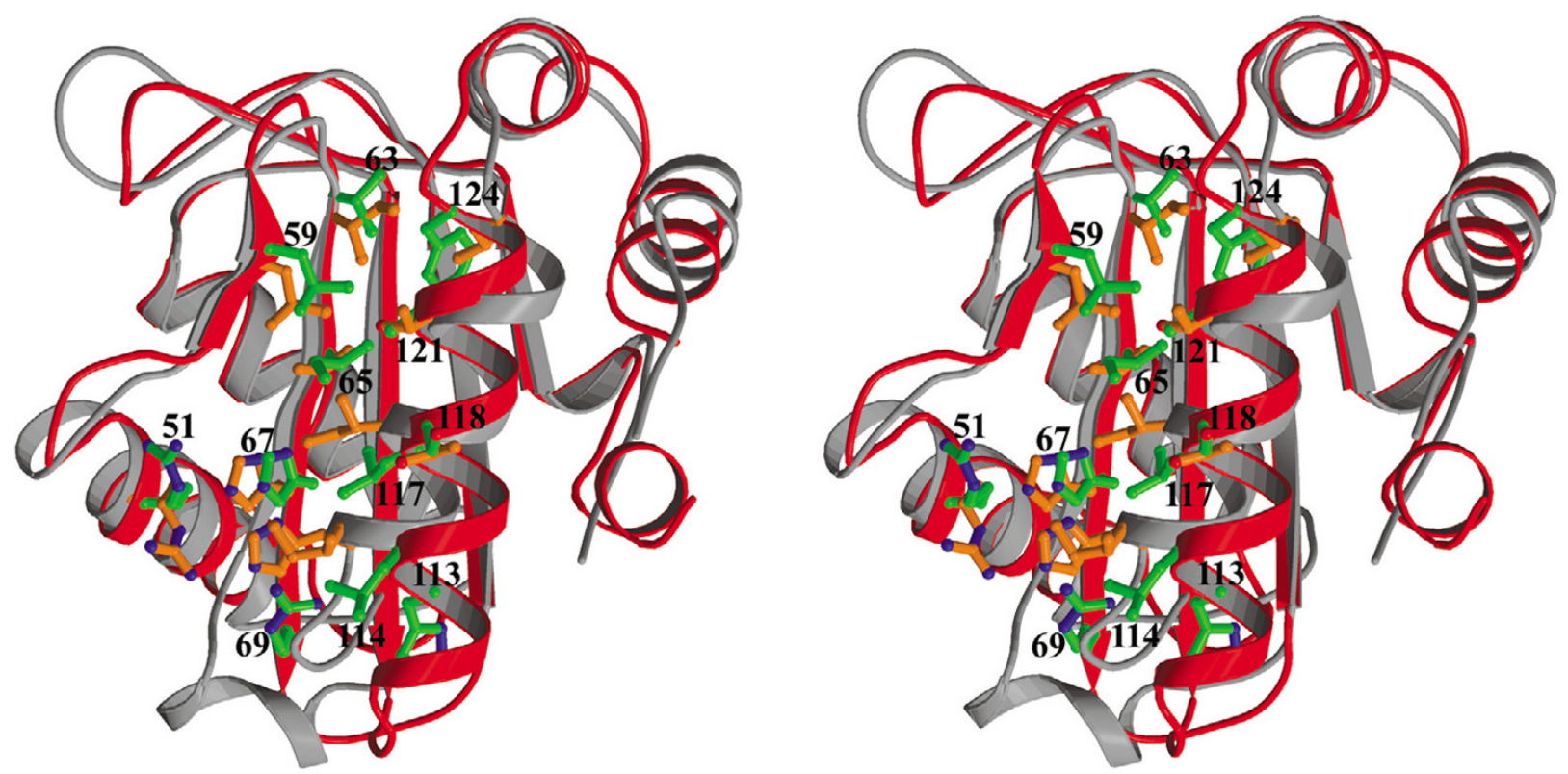

Figure 2

Active site of NM-IIANtr. (a) Stereo figure of an overlay of the active sites of NM-IIANtr (green line for main chain and orange for side-chains displayed as ball-and stick) and E. coli IIA ${ }^{\mathrm{mtl}}$ (grey line for main chain and individual side-chains) showing the positions of residues around the active site $\mathrm{H} 67$ and the sulphate ions observed in the structures of both NM-IIANtr and E. coli IIANtr [9]. Residues are numbered according to the sequence of NM-IIA Ntr. Hydrogen bonds are shown by broken yellow lines and nitrogen, oxygen and sulphur atoms are displayed as blue, red and yellow respectively. (b) Stereo figure of an overlay of NM-IIANtr (red for the main chain ribbon and green for interface residues displayed as ball-and-stick) and E. coli IIAmtl (grey for the main chain and orange for interface residues) showing the relative positions of the residues which form the interface between $E$. coli IIA ${ }^{\mathrm{mtl}} \mathrm{HPr}$ and the corresponding residues in NM-IIANtr. Residues are numbered according to the sequence of NM-IIANtr 
chain hydrogen bonds to the carbonyl groups of both G55 and itself; a similar pattern is also observed in E. coli IIANtr. The side-chain of R69 is folded toward the active site H67 unlike the corresponding $\mathrm{K} 75$ of E. coli IIA ${ }^{\mathrm{Ntr}}$, which is folded away from the active site H73. In the E. coli IIANtr crystal structure there is a sulphate ion forming a salt bridge/hydrogen bonding interactions to the side-chains of both R57 and H73 in one molecule of the crystal asymmetric unit. Interestingly, in our structure there is also a strong peak of electron density located on the 2-fold crystallographic axis, which could be modelled as a sulphate ion interacting with the side-chains of R51, H67 and R69 via salt bridge/hydrogen bonding, as well as to the equivalent residues of the symmetry related molecule (Fig. 2a). The distance from the ND2 atom of $\mathrm{H} 67$ to the two-fold symmetry axis is $3.2 \AA$, providing insufficient space to accommodate a phosphoryl group, consistent with the finding that only un-phosphorylated protein is found in the crystals by mass spectrometry.

In the active site of the E. coli IIAmtl there is a second histidine residue (H111) which is conserved amongst all IIAmt sequences [13] and is proposed by analogy to the glucose PTS to be essential for phosphoryl transfer to the next component in the cascade, IIBmtl[7]. H111 shows two side-chain configurations in both crystal and NMR structures $[10,14]$ either being parallel to and pointing away from, the active site H65 (Fig. 1a). These differing H111 conformations might be related to the two active site geometries required for the phosphoryl group accepting and donating functions of the protein [10]. The equivalent histidine, H113, of NM-IIANtr and H120 of E. coli IIA $^{\mathrm{Ntr}}$ has similar conformations and are located at the back of helix $\alpha 4$ pointing away from the active site. It is unlikely that this histidine can be repositioned at the active site by unwinding the helix and therefore it appears improbable that it play a role in phosphoryl transfer from IIA $^{\text {Ntr }}$ to other proteins. The question arises as to whether another residue in the active site of NM-IIA ${ }^{\mathrm{Ntr}}$ could play a role in phosphotransfer. Intriguingly, R69 in NM-IIANtr is positioned close to the active site and at a similar position to H111 of IIA ${ }^{\mathrm{mtl}}$ (Figure 2a). The structure therefore suggests mutagenesis experiments which could be carried out to investigate further the active site of the protein. More generally, it remains an open question as to how NMIIANtr is de-phosphorylated and whether this results in the phosphorylation of another protein(s). Certainly in $E$. coli, IIA ${ }^{\mathrm{Ntr}}$ cannot substitute for IIA ${ }^{\mathrm{mtl}}$ in the PTS mediated phosphorylation of mannitol [4] and therefore cannot be de-phosphorylated as a consequence of transfer to IIBmtl. Since no IIBNtr component has been identified, it remains unclear what effectors IIANtr proteins bind to and what role phosphorylation plays in this interaction.
By contrast, more is known about the protein(s) that interact with IIANtr to phosphorylate the protein. Again, results from $E$. coli can be used to inform the likely situation in Neisseria. Thus phosphorylation of E. coli IIA ${ }^{\mathrm{Ntr}}$ involves association with the phospho-transfer proteins $\mathrm{HPr}$, as well as the related NPr, and transfer of a phosphoryl group between histidine residues. HPr and NPr are in turn phosphorylated by the upstream histidine kinases Enzyme I (EI) and EI ${ }^{\text {Ntr }}$ respectively, leading to the proposal that there are two parallel phosphoryl transfer chains in E. coli, with NPr the preferential donor to IIANtr [15]. Interestingly in Neisseria meningitidis, there is only one HPr-like protein, encoded by the gene NMB2045. The N. meningitidis HPr-like protein (abbreviated to NM-HPr) shares $32 \%$ and $38 \%$ sequence identity with E. coli $\mathrm{HPr}$ and NPr respectively. Insight into how IIA proteins bind to the upstream effectors has been obtained by nmr studies. A solution structure has been reported for the complex formed between E. coli HPr and IIA ${ }^{\mathrm{mtl}}$ [PDB:1J6T] showing that binding is achieved through a central core of hydrophobic contacts strengthened by a few hydrophilic interactions [11]. It is expected that the interactions between the two Neisseria proteins should resemble the $E$. coli $\mathrm{HPr}$ and IIAmtl complex. Superimposing NM-IIA ${ }^{\mathrm{Ntr}}$ onto E. coli IIAmtl and aligning the HPr sequence with NMHPr have indeed revealed common features of proteinprotein interactions among the two systems. The key residues of the hydrophobic core of E. coli IIA $^{\mathrm{mtl}}$ involved in contacts with HPr are L57, I61, I112, I115, T119 and L122, which correspond to residues L59, V63, L114, L117, A121 and F124 in NM-IIANtr. The aromatic residue F48 of HPr makes most extensive interactions with the hydrophobic core, especially to I61 and L122 of E. coli IIA ${ }^{\mathrm{mtl}}$, whereas in Neisseria the corresponding residues are M48 in NM-HPr, V63 and F124 in IIANtr, an example of change in shape complementarity. However, since helix $\alpha 4$ of NM-IIA ${ }^{\text {Ntr }}$ is 3 residues longer and about $25^{\circ}$ different in orientation compared to the same helix of E. coli IIA ${ }^{\mathrm{mtl}}$, one would anticipate that the NM-HPr could bind in a different orientation. More recently, $\mathrm{nmr}$ has been used to characterise the interaction between E. coli IIA ${ }^{\mathrm{Ntr}}$ and N-Pr [16]. Chemical shift mapping identified the surface on IIANtr for NPr binding, which generally corresponds to the HPr -binding region of IIAmtl but specifically implicates G61, D115, S125, T156 and nearby residues in the interaction. The corresponding residues in NM-IIANtr are G55, N108, S118 and E149, with the region around G55 being the most highly conserved.

\section{Conclusion}

The structure of NM-IIANtr confirms its assignment as a homologue of the IIANtr proteins found in a range of other Gram-negative bacteria. In fact the overall fold of the Neisseria enzyme shows a high degree of similarity to both the IIANtr and IIAmtl proteins from E. coli. Further, the 
orientations of the two histidine residues in the active site region is conserved between the Neisseria and E. coli IIANtr proteins and is distinct from the IIA ${ }^{\mathrm{mtl}}$.

The availability of a second IIANtr structure enables certain generalizations to be made. The effector mechanism of this sub-group of regulatory proteins is distinct from the IIA components of the PTS controlling sugar uptake, which involve a transfer of phosphate via histidine residues to a IIB acceptor protein. The nature of the downstream effectors of IIANtr proteins and the role of IIANtrphosphorylation in the process remain to be established. In contrast, the mechanism of phosphorylation of all IIA components appears to be broadly similar and involves inter-molecular transfer between histidine residues in a complex formed between HPr and IIA proteins. In Neisseria a single HPr-like protein appears to be responsible for phosphorylation of both IIA ${ }^{\mathrm{Ntr}}$ and the IIA components of the sugar PTS whereas in E. coli, there is a parallel pathway involving the HPr-related protein NPr. In E. coli, NPr is expressed, with IIA Ntr and $\sigma^{54}$, from the $r p o N$ operon implying common regulation of gene expression. This is not the case in Neisseria where these genes are found on different transcriptional units. Therefore, although the structure of Neisseria IIANtr indicates that it is part of a similar phosphotransfer cascade to E. coli, details of the regulation of the gene are likely to be distinct.

\section{Methods}

\section{Protein production}

The NM-IIANtr expression construct was generated by means of ligation-independent cloning using Gateway ${ }^{\mathrm{TM}}$ technology (InVitrogen). The NMB0736 gene [Genbank: AE002098 for complete genome sequence] was amplified from genomic DNA (Neisseria meningitidis strain MC58) with $\mathrm{KOD} \mathrm{HiFi}{ }^{\mathrm{TM}}$ polymerase (Novagen) using the forward primer:- 5'ggggacaagtttgtacaaaaaagcaggcttcctggaagttctgttccagggcccgATGAG CCTTATCGGCGAAATTTTG 3 ' and the following reverse primer:5 'ggggaccactttgtacaagaaagctgggtctcaTTATTCTTCAGTCAGGATGGCACG 3'

The PCR product was purified using QIAquick 96 plates (Qiagen) and inserted into the vector pDONR221 by recombination between attB (PCR product) and attP (vector) sequences (BP reaction). The insert from this vector was then transferred in to the expression vector pDEST17 by recombination between attL (pDONOR vector) and attR (pDEST vector) sequences (LR reaction). The expression construct contained the following $\mathrm{N}$-terminal His tag and 3C protease cleavage site (underlined) MAHHHHHHAGFLEVLFQGP. BP and LR reactions were carried out according to the manufacturer's instructions. Recombinant LR clones were identified by PCR using a gene specific forward primer and a T7 reverse primer and verified by DNA sequencing. Protein was produced in the E. coli strain, B834(DE3). The cells were grown at $37^{\circ} \mathrm{C}$ in a $1 \mathrm{~L}$ of GS96 media (QBiogene) to an $\mathrm{A}_{600}$ of 0.6 , induced with isopropyl $\beta$-D-thiogalactopyranoside (IPTG) to $0.5 \mathrm{mM}$ and then incubated for a further $20 \mathrm{~h}$. at $20^{\circ} \mathrm{C}$ reaching an $\mathrm{A}_{600}$ of approximately 5 . The cells were harvested by centrifugation at $6000 \mathrm{~g}$ for $15 \mathrm{~min}$. and lysed using a BasicZ Cell Disruptor (Constant Systems Ltd) at $30 \mathrm{Kpsi}$ in 30 $\mathrm{ml}$ of $50 \mathrm{mM}$ Tris $\mathrm{pH} 7.5$, containing $500 \mathrm{mM} \mathrm{NaCl}, 0.2 \%$ Tween-20. The NM-IIANtr was purified by Nickel affinity chromatography followed by size exclusion chromatography using the standard His Affinity-Gel filtration program on the Akta $3 \mathrm{D}^{\mathrm{TM}}$ (GE Healthcare). After centrifugation at $30000 \mathrm{~g}$ for $30 \mathrm{~min}$., the lysate was loaded onto a $1 \mathrm{ml}$ pre-charged HiTrap ${ }^{\mathrm{TM}}$ Chelating Sepharose ${ }^{\mathrm{TM}}$ FF column (GE Healthcare). The column was washed with $50 \mathrm{mM}$ Tris $\mathrm{pH} 7.5,500 \mathrm{mM} \mathrm{NaCl}, 20 \mathrm{mM}$ imidazole. The protein was then eluted in $50 \mathrm{mM}$ Tris $\mathrm{pH} 7.5,500 \mathrm{mM} \mathrm{NaCl}, 500$ $\mathrm{mM}$ imidazole and injected on to a $16 / 60$ HiLoad $^{\mathrm{TM}}$ Superdex 200 column (GE Healthcare) equilibrated in $20 \mathrm{mM}$ Tris $\mathrm{pH}$ 7.5, $200 \mathrm{mM} \mathrm{NaCl}$. Protein-containing fractions were analysed on SDS-Page gels (Criterion -Biorad). The $\mathrm{N}$-terminal tag was removed by over-night incubation at $4{ }^{\circ} \mathrm{C}$ with His-tagged 3C protease (prepared from a pET24a/His3C expression vector kindly provided by A. Geerlof, EMBL, Heidelberg). The $3 \mathrm{C}$ protease and any uncleaved protein were removed by Nickel affinity chromatography and the protein concentrated to $9.7 \mathrm{mg} / \mathrm{ml}$ using a $5 \mathrm{~K}$ MWCO Vivaspin 15 concentrator (Vivascience) in $20 \mathrm{mM}$ Tris pH7.5, $200 \mathrm{mM} \mathrm{NaCl}, 1 \mathrm{mM}$ TCEP. Mass spectrometry of protein and crystals was carried as described [17].

Table I: X-ray data and refinement statistics

\begin{tabular}{|c|c|}
\hline \multicolumn{2}{|l|}{ X-ray data } \\
\hline Space group & $P 3,21$ \\
\hline Unit cell dimensions ( $a, b, c$ in $\AA$ ) & $61.02,61.02,63.31$ \\
\hline Resolution range $(\AA)$ & $30.0-2.50(2.59-2.50)^{\ddagger}$ \\
\hline Unique reflections & $4988(486)$ \\
\hline Redundancy & $7.6(5.7)$ \\
\hline Completeness (\%) & $100(100)$ \\
\hline Average $I / \sigma(I)$ & $10.2(2.9)$ \\
\hline $\mathrm{R}_{\text {merge }}{ }^{*}$ & $0.183(0.552)$ \\
\hline \multicolumn{2}{|l|}{ Refinement statistics: } \\
\hline No. atoms (protein/water) & $1105 / 73$ \\
\hline$R$-factort $\left(R_{\text {work }} / R_{\text {free }}\right)$ & $0.201 / 0.276$ \\
\hline Rms bond length deviation $(\AA)$ & 0.006 \\
\hline Rms bond angle deviation $\left({ }^{\circ}\right)$ & 1.21 \\
\hline \multicolumn{2}{|l|}{ Ramachandran plot statistics } \\
\hline Residues in most favoured region (\%) & 87.1 \\
\hline Residues in additional allowed region (\%) & 12.1 \\
\hline Residues in generously allowed region (\%) & 0 \\
\hline Residues in disallowed region (\%) & $0.8(\operatorname{Arg} 35)^{\#}$ \\
\hline
\end{tabular}

¥ data in brackets are for the high resolution shell.

$* \mathrm{R}_{\text {merge }}=\Sigma|I-<1>| / \Sigma<1>+\mathrm{R}$-factor $=\Sigma\left|F_{O}-F_{C}\right| / \Sigma F_{O}$;

\# Arg 35 has well defined main-chain electron density. 


\section{Crystallization and data collection}

The protein was crystallized using the nanodrop crystallization procedure with standard OPPF protocols [18] Crystals were grown by the sitting drop vapour diffusion method at room temperature from $3.2 \mathrm{M}$ ammonium sulphate, $0.1 \mathrm{M}$ citrate $\mathrm{pH} 4.0$ over a period of 14 days. Diffraction data were collected at station PX14.2 of SRS (Daresbury, UK). Data images were recorded using an ADSC Quantum 4 CCD detector. A crystal mounted in a fibre loop was placed $250 \mathrm{~mm}$ from the detector and exposed to the X-ray beam with a wavelength of $0.945 \AA$. A total of 69 oscillation images of 2.0 degree per exposure were collected from a single crystal frozen under a stream of nitrogen at $100 \mathrm{~K}$. The diffraction data were indexed and integrated with DENZO [19] and merged with SCALEPACK. The crystal belongs to the trigonal system, with space group of either $P 3_{2} 21$ or $P 3_{1} 21$ and unit cell dimensions of $\mathrm{a}=\mathrm{b}=61.02 \AA$ and $\mathrm{c}=63.31 \AA$. There is one molecule in an asymmetric unit, the crystal has a solvent content of $41.5 \%$ in the crystal. The data set is $100 \%$ complete to 2.5 Å resolution (Table 1 ).

\section{Structure solution and refinement}

The structure was solved using molecular replacement with CNS [20] and the coordinates of E. coli nitrogen regulatory protein IIANtr [PDB:1AGI] as the starting model. The real space cross rotation search was carried out using data from 15-4 $\AA$ and Patterson vectors of 5-24 $\AA$. The cross rotation peaks were then subjected to

PC-refinement with e2e2 target followed by translation search with fastf $2 \mathrm{f} 2$ target. At this stage the space group of the crystal was confirmed to be $P 3_{1} 21$. The highest peak of the translation search $\left(\theta_{1}=150.1, \theta_{2}=68.4, \theta_{3}=82.6, \mathrm{x}=\right.$ $16.5, \mathrm{y}=24.1, \mathrm{z}=-35.0$ ), which is $4.2 \sigma$ above the mean and $3.2 \sigma$ above the $2^{\text {nd }}$ highest one (noise peak), is corresponding to $11^{\text {th }}$ of the 33 cross rotation peaks. Rigidbody refinement of the rotated and translated model at 30-4.0 ̊̊ gave an R-factor of 0.462. Rounds of simulated annealing, conjugate gradient minimization and B-factor refinement followed by model rebuilding and solvent molecule addition with $\mathrm{O}$ have resulted in the current structure which has a $R_{\text {work }} / R_{\text {free }}$ of $0.201 / 0.276$ for all data from 30-2.5 $\AA$ resolution. The rms deviation of the model from the ideal is $0.006 \AA$ for bond lengths and $1.21^{\circ}$ for bond angles (Table 1).

The atomic coordinates of NM-IIA ${ }^{\mathrm{Ntr}}$ and structure factors have been deposited in the Protein Data Bank under the accession code 2A0J.

\section{Authors' contributions}

JR collected and processed the diffraction data, modelled, refined and analyzed the structure, SS purified and crystallized the protein, JN carried out mass spectrometry of the protein and crystals, NB and DA cloned and expressed the protein, NJS initiated the study DKS and RJO coordinated the study. RJO and JR prepared the manuscript with additional input from DKS and NJS.

\section{Acknowledgements}

The Oxford Protein Production Facility is funded by the Medical Research Council UK and is part of the Structural Proteomics IN Europe (SPINE) consortium (European Commission Grant No. QLG2-CT-2002-00988).

\section{References}

I. Parkhill J, Achtman M, James KD, Bentley SD, Churcher C, Klee SR, Morelli G, Basham D, Brown D, Chillingworth T, Davies RM, Davis P, Devlin K, Feltwell T, Hamlin N, Holroyd S, Jagels K, Leather S, Moule S, Mungall K, Quail MA, Rajandream MA, Rutherford KM, Simmonds M, Skelton J, Whitehead S, Spratt BG, Barrell BG: Complete DNA sequence of a serogroup $A$ strain of Neisseria meningitidis Z249 I. Nature 2000, 404:502-506.

2. Tettelin H, Saunders NJ, Heidelberg J, Jeffries AC, Nelson KE, Eisen JA, Ketchum KA, Hood DW, Peden JF, Dodson RJ, Nelson WC, Gwinn ML, DeBoy R, Peterson JD, Hickey EK, Haft DH, Salzberg SL, White O, Fleischmann RD, Dougherty BA, Mason T, Ciecko A, Parksey DS, Blair E, Cittone $H$, Clark EB, Cotton MD, Utterback TR, Khouri H, Qin H, Vamathevan J, Gill J, Scarlato V, Masignani V, Pizza M, Grandi G, Sun L, Smith HO, Fraser CM, Moxon ER, Rappuoli R, Venter JC: Complete Genome Sequence of Neisseria meningitidis Serogroup B Strain MC58. Science 2000, 287:|809-1815.

3. Merrick MJ, Coppard JR: Mutations in genes downstream of the rpoN gene (encoding sigma 54) of Klebsiella pneumoniae affect expression from sigma 54-dependent promoters. Mol Microbiol 1989, 3: 1765-1775.

4. Powell BS, Court DL, Inada T, Nakamura Y, Michotey V, Cui X, Reizer A, Saier MH, Reizer J: Novel proteins of the Phosphotransferease System encoded within the rpoN Operon of Escherichia coli. J Biol Chem 1995, 270:4822-4839.

5. Inada T, Kawakami K, Chen SM, Takiff HE, Court DL, Nakamura Y: Temperature-sensitive lethal mutant of era, a $\mathbf{G}$ protein in Escherichia coli. J Bacteriol 1989, 171:5017-5024.

6. Reizer J: Regulation of sugar uptake and efflux in gram-positive bacteria. FEMS Microbiol Rev 1989, 5:|49-156.

7. Reizer J, Reizer A, Saier MH, Jacobson GR: A proposed link between nitrogen and carbon metabolism involving protein phosphorylation in bacteria. Protein Science 1992, I:722-726.

8. Saier MH, Reizer J: The bacterial phosphotransferase system: new frontiers 30 years later. Mol Microbiol 1994, 13:755-764.

9. Bordo D, van Montfort RLM, Pijning T, Kalk K, Reizer J, Saier MH, Dijkstra BW: The Three-dimensional Structure of the Nitrogen Regulatory Protein IIANtr from Escherichia coli. J Mol Biol 1998, 279:245-255.

10. Van Montfort RLM, Pijning T, Kalk K, Hangyi I, Kouwijzer MLCE, Robillard GT, Dijkstra BW: The structure of the Escherichia coli phosphotransferase IIA ${ }^{\text {mannitol }}$ reveals a novel fold with two conformations of the active site. Structure 1998, 6:377-388.

II. Cornilescu G, Lee BR, Cornilescu CC, Wang A, Clore M: Solution structure of the phosphoryl transfer complex between the cytoplasmic A domain of the mannitol transporter IIMannitol and HPr of the Escherichia coli phosphotransferase system. J Biol Chem 2002, 277:42289-42298.

12. Van Montfort RL, Dijkstra BW: The functional importance of structural differences between the mannitol-specific IIAmannitoland the regulatory IIAnitrogen. Protein Sci 1998 , 7:2210-2216.

13. Reizer J, Reizer A: A voyage along the bases; novel phosphotransferase genes revealed by in silico analyses of the Escherichia coli genome. Res Microbiol 1996, 147:458-47I.

14. Van Dijk AA, Scheek RM, Dijkstra K, Wolters GK, Robillard GT: Characterization of the protonation and hydrogen bonding state of the histidine residues in IIAmtl, a domain of the phosphoenolpyruvate-dependent mannitol-specific transport protein. Biochemistry 1992, 31:9063-9072.

15. Rabus R, Reizer J, Paulsen I, Saier MH: Enzyme INtr from Escherichiai coli. J Biol Chem 1999, 274:26|85-26I91. 
16. Wang GS, Peterkofsky A, Keifer PA, Li X: NMR characterization of the Escherichia coli nitrogen regulatory protein IIANtr in solution and interaction with its partner protein, NPr. Protein Science 2005, 14:1082-1090.

17. Nettleship JE, Walter TS, Aplin R, Stammers DK, Owens RJ: Sample preparation and mass-spectrometric characterization of crystal-derived protein samples. Acta Crystallogr 2005, D61:643-645.

18. Walter TS, Diprose JD, Brown J, Pickford M, Owens RJ, Stuart DI, Harlos K: A procedure for setting up high-throughput nanolitre crystallization experiments. I. Protocol design and validation. J Appl Crystallogr 2003, 36:308-3 I4.

19. Otwinowski Z, Minor W: Processing of X-ray diffraction data collected in oscillation mode. Methods Enzymol 1996, 276:307-326.

20. Brunger AT, Adams PD, Clore GM, Delano WL, Gros P, GrosseKunstleve RW, Jiang JS, Kuszewski J, Nilges M, Pannu NS, Read RJ, Rice LM, Simonson T, Warren GL: Crystallography \& NMR system: A new software suite for macromolecular structure determination. Acta Crystallogr 1998, D54:905-921.

Publish with Bio Med Central and every scientist can read your work free of charge

"BioMed Central will be the most significant development for disseminating the results of biomedical research in our lifetime. "

Sir Paul Nurse, Cancer Research UK

Your research papers will be:

- available free of charge to the entire biomedical community

- peer reviewed and published immediately upon acceptance

- cited in PubMed and archived on PubMed Central

- yours - you keep the copyright

Submit your manuscript here:

http://www.biomedcentral.com/info/publishing_adv.asp 